Journal of Teaching and Learning with Technology, Vol. 10, Special Issue, pp. 229-237.

doi: 10.14434/jotlt.v9i2.31383

\title{
Dialogue in Online Learning Spaces: How Transitioning to Online Learning During a Pandemic Impacts Classroom Dialogue and Inclusivity
}

\author{
Alexandra N. Sousa \\ Indiana University Southeast \\ ansousa@iu.edu
}

Abstract: The sudden shift to online learning because of the 2019 coronavirus disease created a series of challenges for educators. Faculty took a "triage" approach to reformatting their courses quickly. And while this was a necessary approach for many reasons, it was hard not to wonder what students would be missing. As a communication studies professor, I consider dialogue an essential tool in the classroom. Effective dialogue can lead to a greater acceptance of diverse thoughts and individuals, as well as less divisiveness and intolerance. So when the pandemic forced me to switch to online learning, I had many questions: How do we maintain effective classroom dialogue in online learning spaces? How can I create an inclusive classroom online? How does my knowledge of the relationship between dialogue and inclusivity translate to the online classroom? This reflective essay seeks to answer these questions in real time, as I simultaneously prepare to teach at least another year of online courses. I explore the importance of dialogue in the classroom, how dialogue can be a conduit of inclusivity, why educators should strive for inclusivity in our classrooms, and finally, how we translate these lessons to the online classroom. My hope is that this piece will help further this conversation and act as a resource for maintaining effective dialogue in every type of classroom.

Keywords: online learning, dialogue, inclusivity, COVID-19.

It is no surprise that the shift to online learning because of the 2019 coronavirus disease (COVID-19) created a series of challenges for teachers in higher education. The change was sudden and undefined. Many quippy, self-help-style mantras circulated our email inboxes:

You can do it!

No one is perfect.

Do the best you can!

And while these catchphrases were certainly valuable to embrace in some way, it was still hard not to think about all that students would miss. Unfortunately, many of us also initially thought this would be short-lived.

In the early summer of 2020, when COVID-19 had not been properly contained, it became clear that widespread online learning would continue for the foreseeable future. Teachers could no longer take the "triage" approach and simply find a quick fix to teach online temporarily. They would have to be more purposeful with pedagogical decisions and course design.

At the time, the good news was that educators generally accepted online learning as an effective teaching format. The bad news was that despite said knowledge, those of us who prefer to teach in person were still willfully pessimistic about the idea. As a professor in Communication Studies, a discipline grounded in interaction, I doubted that I would be able to replicate online what I had been doing in the physical classroom.

Most notably, I questioned how I would be able to facilitate effective dialogue with my students online. I believe one of the most important tools we can give our students is the ability to 
communicate well. Effective dialogue leads to a deeper understanding of others and a greater acceptance of diverse thought and people. As Ramasubramanian and Wolfe (2020, para. 2) expressed so eloquently, "At its best, dialogue promises to bring together people with different worldviews, life experiences, stakes, interests, and goals and provide opportunities for perspective-taking, learning, open-mindedness, and turn-taking." Dialogue is an important tool for promoting inclusivity in the classroom. So when the pandemic forced us to switch to online learning, I had many questions: How can I maintain effective classroom dialogue in online spaces? How can I create an inclusive classroom online? How does my knowledge of the relationships between dialogue and inclusivity translate to the online classroom?

In this reflective essay I explore these questions in real time, as I simultaneously prepare to teach at least another year of online courses. I look at the importance of dialogue in the classroom, how dialogue can be a conduit of inclusivity, why we should strive for inclusivity in our classrooms, and finally, how we translate these lessons to the online classroom.

\section{The Importance of Dialogue in the Classroom}

Many people use the terms "discussion" and "dialogue" interchangeably. However, there are important distinctions between the two. Discussion seeks to settle an issue and often implies the necessary presence of argumentation, refutation, and debate (Nash, Bradley, \& Chickering, 2008). Dialogue is more open and the goal is mutual understanding, not "winning" (Nash et al., 2008; Ramasubramanian \& Wolfe, 2020).

Although discussion and dialogue both have an important place in the classroom, many educators tend to utilize discussion (Nash et al., 2008). However, the intense political and social divisiveness in the United States that has been heightened by responses to COVID-19 highlights the need to bring dialogue into the classroom now more than ever. As Nash et al. (2008) explained, "Too many discussions of controversial topics in the American university tend to foster a culture of contestation, not a culture of conversation. All of us on college campuses are conditioned to think of communication as debate, not dialogue" (p. 5). And it makes sense that this would translate into our teaching. Dialogue, on the other hand, is a necessarily tension-filled process characterized by active listening, expressing one's viewpoint without simultaneously dismissing another, and engaging with emotion, passion, and conflict (Barge, 2006; Pearce \& Pearce, 2004). Since mutual understanding is the goal, no one has to be "right" or "wrong," and one can still hold firmly to one's own beliefs while legitimatizing others' perspectives.

One of the hardest aspects of having productive dialogue in the classroom is that it requires participants to bring forth their most authentic selves. However, educators can stifle this in themselves and their students in several ways. For example, traditional ideas of what it means to be a college educator have shaped our performances in the classroom, creating a stark power difference between student and teacher, and the result can be a lack of authenticity. Johnson and LaBelle (2017) found that students attributed approachability, passion, attentiveness, and expertise to authentic teachers. However, this authenticity is derived not from teachers' behaviors but from students' "perceptions that teachers were acting out of genuine concern, respect, and care for students" (Johnson \& LaBelle, 2017, p. 434). Relatedly, vulnerability is an important quality to have. I think it is still possible to garner respect from students while being vulnerable and willing to share our own personal experiences.

Authenticity must also be reflected in the structure of courses. The notion of creating a "safe space" in the classroom is quite popular but this typically happens just on the surface. I can say I value students' right to hold different political stances but if I were to show only media examples that exist on one end of the political spectrum, I would be inadvertently making statements about where my 
students should stand. This communicates that I am not interested in understanding their perspective if it is different from my own.

Being more authentic and open as educators requires balance. As a nonreligious, politically liberal woman who has worked at universities where conservatism and religion are held in high regard by many students, it has taken a lot of personal reflection to find a way to establish two-way openness and honesty. I don't have to be inauthentic to myself and I shouldn't expect that of my students. Dialogue requires this to be effective, and I can't say I've always succeeded. Difficult conversations in the classroom are intimidating and I'm not void of that fear even as a communication scholar. Being able to facilitate dialogue is not necessarily an inherent quality. It takes practice. It's also important to have realistic expectations for what dialogue can accomplish. I believe it is a critical tool for facilitating change, but it will not change the world in and of itself.

\section{Dialogue and Inclusivity}

Conversations about COVID-19 have also coincided with those involving the Black Lives Matter movement. Although the topics of health and equity are often talked about disparately, they are inextricably linked. COVID-19 has amplified harmful health, income, and racial disparities that exist within the United States (Diversity and Inclusion During the COVID-19 Crisis, 2020), much of which has been rightfully highlighted by the Black Lives Matter movement. Inclusivity should always be a central aim of higher education institutions, but it has become increasingly important for us to meaningfully engage in these discussions.

Although there are many important changes that must be made to address inequities within higher education, dialogue is a tool that can be utilized right now. Dialogue is a way into others' experiences, an avenue to better understanding the realities of higher education and its impacts on marginalized students. According to educator and philosopher Paulo Freire, who often theorized about the connections between education, societal inequities, and dialogue, dialogue is the means through which students can move from what he referred to as "naïve consciousness" to "critical consciousness." To do so, students "need to engage in the social process of dialogue and this dialogue needs to be equal. This dialogue consists of the student reflecting on the unjust aspects of their reality and working towards solutions to transform them" (Ali, 2018, p. 210). Although one can critique Freire's work in many ways, many of his contributions about dialogue and education are still important (hooks, 1994). Dialogue not only is a way that marginalized individuals can engage with and express their realities but also allows those who are more privileged to challenge their own perspectives of the world.

It is important to create an inclusive classroom to establish a foundation for dialogue that promotes inclusivity. This, however, is a complex task. Even clear definitions of "diversity" and "inclusion" are hard to come by because they are incredibly multifaceted terms (Kvam, Considine, \& Palmeri, 2018). My own research explores issues of inclusion within higher education and admittedly, any points I make in this essay will be just a cursory glance at these topics. That being said, I still think it's highly important to talk about the ways dialogue can be a conduit for promoting equity and inclusion in the classroom.

An inclusive classroom is one that does not shy away from conversations about the complexity of identity, difference, and power. There are many constructs that form the unique identities of college students and it's important to be more purposeful with what we address. In higher education, the focus is often on race, ethnicity, gender, sexuality, and ability; yet, there are other important identities and intersections of identities that deserve attention. Of course, not every class can touch on everything, but every class can do more. There are many tips for creating an inclusive classroom, but there are a few I will highlight here. First, educators have to be willing to learn. These are complicated

Journal of Teaching and Learning with Technology, Vol. 10, Special Issue, jotlt.indiana.edu 
topics that requires us to continually educate ourselves and be reflexive. Likewise, it is critical to know who we are as educators, including our own identities and levels of comfort with personal disclosure and fear of emotional intensity and losing control in the classroom (Adams, Bell, \& Griffin, 2007). It's also important to diversify the readings, examples, and activities we use.

Kvam et al. (2018) urged us to consider the language we use to talk about issues of inclusion within the classroom because our language is "not power-neutral but [is] inherently power-laden" (p. 288). It is not enough simply to talk about these important issues; bow we talk about them is equally important. For example, Kvam et al. (2018) suggested shifting our language from diversity to difference because the term "diversity" has become so ambiguous and arguably meaningless in educational contexts. The goal is to get students to think about these concepts in new, complex ways that reveal the "power, privilege, and systemic inequity" that exists within our discourse (p. 289).

Difficult dialogues in the classroom, especially those related to inclusivity and equity, require a lot of reflexivity from participants. To help students reflect on their own perspectives before asking them to engage with others, I find it helpful to pair dialogue with a written assignment (Antony, 2016). Students are often weary of dialogue about these topics, so it gives them a chance to parse out their thoughts, ways to frame their arguments, and evidence they want to present. It also allows them to consider others before presenting their thoughts. Although dialogue should be authentic and honest, it's important to make sure students frame their arguments as respectfully as possible.

Most importantly, avoid putting marginalized students in a position where they have to relive traumatic experiences. All students should share deeply personal experiences only if they are comfortable and willing. A key to this is addressing your own problematic and harmful assumptions as an educator because it is far too easy to reinscribe harmful beliefs and behaviors that hurt those you intended to help (Saunders \& Kardia, 1997).

\section{Complexities of the Online Classroom}

The importance of dialogue in the physical classroom is relatively well established but online learning formats complicate this conversation. Although research in this particular subject area is scant, dialogue and inclusivity are still critical in an online course and we can begin to make important observations about how they interact.

To begin, meaningful connectivity is not lost in synchronous learning spaces but is simply different. One important framework that has been used to explore student-teacher interactions in online courses is social presence theory. At a basic level, the theory argues that educators' social presence in online classes is characterized by immediacy and intimacy, how long it takes them to respond, and the quality of interpersonal relationships established; as immediacy and intimacy go up, so do student learning and satisfaction (Baker, 2010; Dalhstrom-Hakki, Alstad, \& Banerjee, 2020; Richardson \& Swan, 2003). Subsequent studies have shown this correlation is not quite as straightforward as originally conceived, but there are still important takeaways.

Although verbal and nonverbal physical behaviors are typically not present in synchronous online courses, Baker (2010) noted that there are many effective verbally immediate behaviors that can be utilized, including "initiating discussions, asking questions, using self-disclosure, addressing students by name, using inclusive pronouns (we, us), repeating contacts with students over time, responding frequently to students, offering praise, and communicating attentiveness" (p. 5). Combinations of these behaviors can be utilized across several mediums in an online course, including discussion posts, assignment feedback, announcements, and video, to create strong interpersonal relationships with students. 


\section{Online Dialogue}

None of these techniques for communicating with students online are inherently dialogic. As mentioned above, dialogue is a tension-filled process with no specific end beyond greater understanding. Many times when teachers elicit "conversation" in online courses, they require students to have a finite answer, critique, or opinion. For example, when COVID-19 forced me to reconfigure my classes this spring, I often resorted to having my students answer discussion questions about their reading. While this type of assignment is helpful in some ways, it did not properly reflect the discussions and dialogues we would likely have had about these topics had we still been in the physical classroom. So, I spent much of this summer thinking about how I could incorporate the characteristics of dialogue more effectively into my online courses.

Discussion posts and groups are an easy place to start to theorize about the role of dialogue in online learning. For fully synchronous courses, discussions posts are the central avenue through which you can engage with your students and have students engage with each other. As Boothe (2018) explained, "By engaging a community of learners in discussions related to teaching and learning, students are motivated and challenged to high ideals and positive outcomes" (pp. 70-71). Although this is not something I have explored in my own courses yet, there is also the possibility of incorporating chat technologies such as Google Chat or Slack, to better mirror real-time conversations. Online chat is not only useful for facilitating discussion between students; teachers can also use it to identify students who are struggling and provide feedback efficiently (Shibani, Koh, Lai, \& Shim, 2017). Discussion formats like these can be important spaces to increase immediacy and intimacy. However, regardless of the mode of discussion, there are a couple of dialogic goals to keep in mind when utilizing these communicative technologies in online classrooms.

As I noted before, authenticity of participants is important in dialogue. Unfortunately, "technologically mediated discussions" in synchronous classes can be seen as inauthentic and forced, partly because there is a lack of nonverbal cues and body language (Montelongo \& Eaton, 2020). However, there are ways we can try to mitigate this. First, respondents do not always have to respond with written text. They can utilize video and audio to respond to each other. This way, thoughts don't seem so scripted and nonverbal communication is possible. Likewise, educators should still construct a discussion space where respondents (including teachers themselves) feel safe to share personal experiences and be vulnerable.

Teachers must also make purposeful decisions about how to frame online discussions. Educator presence in this context includes "presenting content and questions, focusing the discussion on specific issues, summarizing discussion, confirming understanding, diagnosing misperceptions, injecting knowledge from diverse sources, and responding to student's technical concerns" (Baker, 2010 , p. 24). When guided by dialogue, educators still assume many of these same responsibilities but with a certain sensibility. Discussion prompts and questions need to be framed in a way that they do not seek finite answers or solutions to prompts. Greater understanding can still be the goal. Likewise, teachers must emphasize the importance of not dismissing others' thoughts and, in the vein of active listening, attempting to fully understand what is expressed by another before responding.

Of course, the advent of video meeting technologies such as Zoom and Skype has made dialogue more plausible in online learning. Participants can witness nonverbal cues and expressions, and the back-and-forth of conversation more closely resembles that which would happen in person. However, communication still does not translate in the exact same way. For one, technological and connectivity issues still obstruct clear communication often. Participants may have unreliable internet connections and the newness of these mediums creates hesitation to compete with the many voices present on the screen. Similarly, students are still concerned with how they look and sound, and with dozens of sets of eyes compacted on them, the pressure to "perform" can be even greater.

Journal of Teaching and Learning with Technology, Vol. 10, Special Issue, jotlt.indiana.edu 


\section{Online Inclusivity}

Inclusivity is an interesting conversation to have in the context of online learning. Unfortunately, online classes are often presumed to be more inherently equitable learning environments. Oztok (2020) noted that communication in online spaces can open the door to those who are usually left out of conversations. Marginalized groups "can benefit from the increased possibilities for participation" (p. 4). However, online technologies are not inherently inclusive or value neutral. Assuming so would ignore the power structures and culturally hegemonic practices that are still very much at play in online learning spaces. As Montelongo \& Eaton, (2020) explained:

Critical digital pedagogy argues that technology is neither neutral nor value free and should be examined through how technologies perpetuate social inequities in patterning and (re)producing dominant modes of relationality. Put differently, digital technologies manifest in perpetuating dominant attitudes, assumptions and agendas to crystallize particular ways of knowing and being in the (online) classroom. (p. 34)

Conversations about inclusivity in online learning environments need to go beyond issues of "access" and technological determinism (Oxtok, 2020) because there are still many opportunities for inequitable communication and learning conditions.

There are several ways as educators that we can create a more inclusive classroom online. More finite suggestions include being less stringent with deadlines and "unexcused" absences (Mehta \& Aguilera, 2020), captioning all videos and media examples, and offering lecture material in multiple formats if needed. On a more macro level, it is still incredibly important to cultivate relationships with students (Mehta \& Aguilera, 2020). Likewise, there should still be ample opportunities for discussion and the sharing of personal experiences.

When it comes to difficult dialogues in particular, many of the same techniques for the physical classroom still apply in online learning spaces. First, educators must still be willing to have conversations about difficult topics online and challenge harmful assumptions that are negatively impacting marginalized groups. We must be purposeful with the language we use, the engagement expectations we set for our students, and the goals we have for dialogue. Creating an inclusive classroom structure still serves as the base for effective dialogues on potentially difficult topics. But again, we must not assume online classes are inherently inclusive or we run the risk of reinforcing vulnerabilities placed on marginalized students.

To help students become more comfortable with having these types of conversations, I created a version of the game "Would You Rather?" that I use at the beginning of each semester. Before the activity begins, a couple of important things happen. First, I explain to students what we are going to be doing and that the goal is not to change anyone's mind, but simply to gain a better understanding of the diverse individuals in the class. Next, given this goal, my students and I coconstruct "ground rules" for the dialogue we are going to have. Example rules include practicing active listening, not speaking for others or other groups, and assuming others come with good intentions. Then, the activity can begin.

I ask students to stand as a group at the front of the class and then I present them with a series of prompts where they have to "choose a side." They then move to the side of the class that best represents their perspective. When I do this online, I ask students to write " $A$ " and "B" on two small pieces of paper to hold up to designate which side they would choose. It's also important to have a neutral zone, for those who are uncomfortable picking a finite answer. These prompts are meant to be somewhat contentious and include: "I am a feminist, yes or no," "I believe in climate change, yes 
or no," "I am a conversative or I am a liberal." Once students move to their respective side, I open up the floor for students to talk about why they are where they are in the room. Sometimes it gets heated and that is okay. But what typically happens is that students begin to realize they have far more in common with those they think "oppose" their perspective. It evolves into a conversation about the dangers of tribalism and the importance of being in conversation with those we think are different from us. The outcome is usually quite profound, for them and for me.

\section{Having Dialogue in the Classroom}

Whether we are talking about traditional or online learning, I think it is important to close this reflective essay with a list of techniques to help facilitate dialogue in general. Having effective dialogue in your classrooms simply begins with a willingness to try. Although I am still honing my own facilitation skills, I have found the following tips to be particularly helpful for conducting dialogues in the classroom:

1. Establish the opportunity for authentic engagement from the moment class begins. Christopher (2015) recommended the following for online interactions, although I think they also apply to in-person classes:

- Greet each student, even virtually.

- Pay particular attention to how you, the educator, communicate. Be clear and excited to engage.

- Be extra attentive to feedback, including nonverbals (if possible) and chat boxes/discussion posts.

2. Be intentional and clear about your goals for the dialogue, but don't be unrealistic and don't force it.

3. Allow students to be part of the process. Allow them to coconstruct "ground rules," questions, and goals for dialogue with you.

4. Reinforce important expectations for dialogue. Ramasubramaniam, Sousa, and Gonlin (2017) offered the following as a foundation for such communication:

- Active listening - Listen to understand, not only to respond.

- Balanced airtime - If you usually talk a lot, let other voices be heard. If you are typically quieter, try to get out of your comfort zone and share.

- Confidentiality - Who says what should stay in the room; opinions offered here should not have consequences for participants outside of this safe space. Discussing issues is OK; discussing names is not.

- Assume good intentions-Everyone has different levels of understanding about certain issues, so give others the benefit of the doubt.

- Make "I" statements_ “I think that..." "My experience is..." Don't say "Those people are..."

- Avoid vulgar language

5. Don't shy away from discussing the uncomfortableness of dialogue, even your own.

6. Allow students to prepare for a difficult dialogue. Give students the opportunity to be reflexive before communication begins. It will give them an opportunity to fully form their thoughts and aid in their comfortableness with sharing.

7. Allow for closure and reflection, a suggestion offered by Ramasubramanian and Wolfe (2017). 
- Make sure the conversation does not stop; give students other action steps to continue the learning process once the formal discussion is over.

- Give students an opportunity to write down their thoughts after the discussion and make sure to follow up with students and/or the class if the conversation seems incomplete.

- Example questions to ask: What in the readings was new information for you? What did you find confusing or surprising? How does this challenge your thinking or beliefs?

This list is just a starting place and nowhere near comprehensive. Because research in many of these areas is still developing, I welcome critiques, challenges, and extensions to what I've offered here. It is quite clear that online learning is here to stay. Even after the immediate effects of the COVID-19 pandemic have passed, this remains an important field of study. Facilitating effective dialogue and promoting inclusivity within our classrooms are important goals, whether or not we teach online and whether or not we are in a pandemic. Despite all the setbacks we have experienced because of COVID-19, it has provided the opportunity to reflect on how educators approach pedagogy and course design.

This is still very much a learning process for us all. In many ways, I'd like to blame the pandemic for my unpreparedness to teach online unexpectedly last spring, but that wouldn't be entirely fair. In many ways, I should have already been prepared. I'm an educator in 2020, after all. But hindsight is also 20/20. So instead, I'm choosing to look at this as an opportunity for us all to be better prepared for the many different shapes our classes can take, now and in the future.

\section{Epilogue}

As I reflect on the past year, many of the questions I first posed seem less daunting to answer. I've become more confident in my teaching abilities online, and the role that dialogue and inclusivity play in the virtual classroom. That being said, this all still feels far from "normal." It is hard to separate my experience with online teaching with the COVID-19 crisis that initiated it. Or the mental exhaustion I still see in my students every week. I think we should all give ourselves credit for our willingness and ability to adapt during this time, while simultaneously holding onto the importance of continuing to learn more from teaching during a pandemic.

\section{References}

Adams, M., Bell, L. A., \& Griffin, P. (Eds.). (2007). Teaching for diversity and social justice (2nd ed.). New York, NY: Routledge.

Ali, Y. (2018). Using a Freirean approach within the Global Youth Solutions Programme. In A. Melling \& R. Pilkington (Eds.), Paulo Freire and transformative education: Changing lives and transforming communities (pp. 203-214). London, England: Palgrave Macmillan.

Antony, M. G. (2016). Exploring diversity through dialogue: Avowed and ascribed identities. Communication Teacher, 30(3), 125-120. https://doi.org/10.1080/17404622.2016.1192663

Baker, C. (2010). The impact of instructor immediacy and presence for online student affective learning, cognition, and motivation. The Journal of Educators Online, 7(1), 1-30. https://doi.org/10.9743/JEO.2010.1.2

Barge, J. K. (2006). Dialogue, conflict, and community. In J. G. Oetzel \& S. Ting-Toomey (Eds.), The SAGE bandbook of conflict communication (pp. 517-544). Thousand Oaks, CA: SAGE Publications. 
Boothe, D. (2018). Discussion groups and online learning. Cognitive Science-Mew Media - Education, 4(1), 67-78. https://doi.org/10.12775/CSNME.2018.005

Christopher, D. (2015). The successful virtual classroom: How to design and facilitate interaction and engaging live online learning. New York, NY: American Management Association.

Dalhstrom-Hakki, I., Alstad, Z., \& Banerjee, M. (2020). Comparing synchronous and asynchronous online discussion for students with disabilities: The impact of social presence. Computers \& Education, 150,1-11. https://doi.org/10.1016/j.compedu.2020.103842

Diversity and inclusion during the COVID-19 crisis. (2020). Duke University School of Medicine. Retrieved December 21, 2020 from https://medschool.duke.edu/about-us/diversity-andinclusion/office-diversity-inclusion/resources/diversity-and-inclusion-during-covid-19-crisis

hooks, b. (1994). Teaching to transgress: Education as the practice of freedom. New York, NY: Routledge.

Johnson, Z. D., \& LaBelle, S. (2017). An examination of teacher authenticity in the college classroom. Communication Education, 66(4), 423-439. https://doi.org/10.1080/03634523.2017.1324167

Kvam, D. S., Considine, J. R., \& Palmeri, T. (2018). Defining diversity: An analysis of student stakeholders' perceptions of a diversity-focused learning outcome. Communication Education, 67(3), 287-307. https://doi.org/10.1080/03634523.2018.1465189

Mehta, R., \& Aguilera, E. (2020). A critical approach to humanizing pedagogies in online teaching and learning. The International Journal of Information and Learning Tecbnology, 37(3), 109-120. https://doi.org/10.1108/IJILT-10-2019-0099

Montelongo, R., \& Eaton, P. W. (2020). Online learning for social justice and inclusion: The role of technological tools in graduate student learning. The International Journal of Information and Learning Technology, 37(1/2), 33-45. https://doi.org/10.1108/IJILT-11-2018-0135

Nash, R. J., Bradley, D. L, \& Chickering, A. W. (2008). How to talk about hot topics on campus. San Francisco, CA: Wiley.

Oztok, M. (2020). The hidden curriculum of online learning: Understanding social justice through critical pedagogy. New York, NY: Routledge.

Papendieck, A. S. (2018). Technology for equity and social justice in education: A critical issue overview. Texas Education Review, 6(1), 1-9. https://doi.org/10.15781/T2891278V

Pearce, W. B., \& Pearce, K. A. (2004). Taking a communication perspective on dialogue. In K. Anderson, L. A. Baxter, \& K. Cissna (Eds.), Dialogue: Theorizing difference in communication studies (pp. 39-56). Thousand Oaks, CA: SAGE Publications.

Ramasubramanian, S., Sousa, A., \& Gonlin, V. (2017). Facilitated dialogues to combat racism: A goal-based approach. Journal of Applied Communication Research, 45(5), 537-556. https://doi.org/10.1080/00909882.2017.1382706

Ramasubramanian, S., \& Wolfe A. (2017). Facilitating hot topics in the classroom. Workshop for faculty at Texas A\&M University, College Station, TX.

Ramasubramanian, S., \& Wolfe, A. W. (2020, July 9). The promise and perils of interracial dialogue. NCA: Communication Currents. Retrieved from https://www.natcom.org/communicationcurrents/promise-and-perils-interracial-dialogue

Richardson, J. C., \& Swan, K. (2003). Examining social presence in online courses in relation to students' perceived learning and satisfaction. Journal of Asynchronous Learning Network, 7(1), 68-88. https://doi.org/10.24059/olj.v7i1.1864

Saunders, S., \& Kardia, D. (1997). Creating an inclusive classroom. University of Michigan. Retrieved from http://crlt.umich.edu/gsis/p3 1

Shibani, A., Koh, E., Lai, V., \& Shim, K. J. (2017). Assessing the language of chat for teamwork dialogue. Educational Technology \& Society, 20(2), 224-237. 